\title{
Sombra de Prédios e Torres em Cidades e de Montanhas na Região Rural
}

\author{
The Shadows Cast by Buildings and Towers in Cities and by Montains in the Countryside
}

\author{
João Luiz Kohl Moreira* \\ Coordenação de Astronomia e Astrofísica, Observatório Nacional - MCT \\ Rua Gal. José Cristino, 77, 20921-400, Rio de Janeiro, RJ
}

Recebido em 2 de dezembro, 2002. Aceito em 27 de janeiro, 2003.

\begin{abstract}
É freqüente a pergunta endereçada aos astrônomos do Observatório Nacional sobre como a sombra de um dado edifício ou torre a ser construída em área de grande densidade populacional incidirá sobre a região, trazendo, ou não, prejuízos ao bem estar de uma população, privada do acesso à luz solar. O mesmo problema se dá, com respeito ao planejamento de áreas cultiváveis de acordo com a topografia da região e sua localização geográfica. A prática adotada entre meus colegas é a de simplesmente enviar "fórmulas" da trigonometria esférica, além das equações do movimento do Sol, transferindo a responsabilidade das conclusões aos engenheiros e agrônomos envolvidos com o problema. O que não nos ocorre, a nós, astrônomos, nesses casos, é a eventual, e até mesmo provável dificuldade daqueles profissionais em tratar o problema, visto que é necessário um certo conhecimento de astronomia fundamental e posicionamento dos astros para se poder abstrair os movimentos que o Sol pode fazer. Projeções e mapeamento da sombra na planta baixa de uma região também requer prática e conhecimento específico. Esse trabalho se propõe a sanar essas dificuldades, apresentando soluções que, ao final, oferecerão aos profissionais, professores, estudantes e interessados, condições de compreenderem melhor a questão e, talvez, pelo menos em alguns casos, de dispensarem consultas aos astrônomos.
\end{abstract}

\begin{abstract}
Often astronomers of the Observatório Nacional are asked about how the shadow cast from a building or a tower to be built will impact crowded areas; in which way they would interfere with the wellfare by depriving population from sunlight. The same problem arises when agronomers plan areas for cultures when topographical accidents may cast shadows in a geographic region. My colleages usually answer these questions by delivering spherical trigonometry formulae and the sun equations of movement, and therefore they transfer the responsability of the conclusions back to the engineers and agronomers. What we didn't realize is the possible and even probable difficulties that these professionals could be facing, since fundamental astronomy and astronomical object positioning knowledge is needed to figure out how the sun moves in the celestial sphere. Shadow projection and its mapping on a ground plan also requires specific knowledge. This paper intends to introduce solutions that will offer professionals, teachers and students conditions of better understanding this problem and, possibly, at least in some cases, bypass the need for quering astronomers.
\end{abstract}

\section{Introdução}

O estudo das localizações e movimentos que as sombras de objetos e volumes podem fazer por obstrução da luz solar destina-se a trazer subsídios a engenheiros, agrônomos, arquitetos, cartógrafos, artistas, ambientalistas, professores e responsáveis públicos pelas questões do bem estar, programação de áreas cultiváveis, planejamento urbano, construção civil, efeitos artísticos ou, simplesmente, interesse didático em construir relógios solares e miras. A proposta deste trabalho é apresentar uma análise qualitativa, sem, por isto, perder eficiência na previsão do que pode ou não acontecer em uma região contendo montanhas e/ou torres, volumes enfim, que provocam sombra quando são iluminados pelo sol. Essa análise pode ser de grande utilidade na elaboração de uma política de urbanização, na decisão de onde estabelecer uma locação para filmagens ou na delimitação de áreas para cultivo de diferentes produtos agrícolas. Entretanto, este trabalho não se destina ao auxílio à reconstituição ou perícia forense, mais exigentes quanto à exatidão na determinação do dia, hora e local dos eventos. As aproximações que pudemos fazer permitem uma significativa simplificação da análise, tornando esse artigo também acessível a professores e estudantes de física e matemática.

A compreensão do comportamento da sombra implica em algum conhecimento do movimento solar, da astronomia de posição, seus fundamentos e seus métodos. Além disso o estudo da formação de sombra pode despertar o in-

*kohl@on.br, http://maxwell.on.br/ kohl 
teresse na astrometria, ciência um pouco esquecida nos dias de hoje por conta das áreas astrofísicas, muito mais vistosas e sedutoras para os estudantes que ingressam na carreira da astronomia.

Iniciarei por fazer um breve apanhado do movimento do Sol na esfera celeste, tanto no que diz respeito à projeção do movimento orbital da Terra (Seção II), quanto do movimento de rotação da Terra (Seção III). Aproveito para fazer uma breve introdução à trigonometria esférica sem, contudo, deter-me nos detalhes. Uma descrição completa e razoavelmente bem aproximada do movimento do Sol é apresentada na Seção III. Faço uma análise específica das propriedades do movimento geral dos astros e do Sol, em particular com respeito às coordenadas do local.

Em seguida apresento alguns aspectos da análise do movimento do Sol nas diferentes estações do ano, tendo como objeto de análise a topografia local (Seção IV) e a projeção da sombra sobre a planta baixa de uma região. Sugiro a construção de diagramas que facilitem a análise do que pode ocorrer no local (Seção V).

Finalmente, proponho o exame da forma de uma sombra em função do objeto em local acidentado (Seção VI) e termino por discorrer sobre a penumbra, sombra semiiluminada que aparece nas extremidades das sombras dos anteparos (Seção VII).

\section{O Movimento Anual do Sol}

Por conta do movimento orbital da Terra, o Sol projetado na esfera celeste movimenta-se sobre uma linha média chamada eclíptica. Tal linha descreve uma circunferência sobre a esfera celeste, fazendo com o equador um ângulo de, aproximadamente, $\varepsilon=23^{\circ} 26^{\prime}$. Tal ângulo é conhecido como obliquidade da eclíptica e, usualmente, é representado pela letra grega $\varepsilon$. Os pontos de cruzamento entre a eclíptica e o equador são chamados de equinócio vernal (ponto $\gamma$ ) e equinócio outonal, e representam respectivamente o início da primavera e do outono, na convenção do hemisfério norte. Na esfera celeste, o Sol atinge dois pontos extremos com respeito ao equador que marcam a entrada do verão (solstício do verão) e do inverno (solstício do inverno). Esses extremos distam do equador de $|\varepsilon|$. A Figura 1 mostra o esquema da esfera celeste, contendo o equador, a eclíptica, os pontos norte e sul e o sol sobre a eclíptica. A posição do sol na eclíptica, com origem no ponto $\gamma$ é chamada de longitude celeste $(\ell)^{1}$. Com respeito ao equador, as coordenadas do Sol são a ascenção reta $(\alpha)$ e a declinação $(\delta)$. A origem da ascenção reta é, igualmente, o ponto $\gamma$ e toma valores entre 0 e $24^{h}$. Já a declinação é nula no equador e toma valores entre $-90^{\circ}$ (pólo sul) e $+90^{\circ}$ (pólo norte). A equação que descreve o valor da longitude do Sol na eclíptica com o tempo, é colocada na forma de série de potências [1]:

$\ell^{(\circ)}=280,46646+36000,76983 T+0,0003032 T^{2}+0\left(T^{3}\right)$, tomando-se $T$ o tempo como fração do século juliano, que contém 36525 dias, a partir de J2000.0 (01/01/2000 às 12:00 horas). Os termos em segunda ordem e superior representam as variações devidas às perturbações por grandes planetas. Para o nosso interesse esses termos podem ser desprezados. O termo em primeira ordem diz respeito ao arco de $360^{\circ}$ percorrido em um ano, adicionado de um termo de perturbação em primeira ordem ( $\sim 46^{\prime}$ por século juliano). Para efeito da análise desenvolvida neste artigo, será suficiente estabelecer que a longitude do Sol percorre um arco de $360^{\circ} \mathrm{em}$ um ano. Da trigonometria esférica [3] e da análise da Figura 1 deduzimos que:

$$
\begin{aligned}
\operatorname{sen} \delta & =\operatorname{sen} \varepsilon \operatorname{sen} \ell \\
\cos \alpha & =\cos \ell / \cos \delta \\
\operatorname{sen} \alpha & =\cos \varepsilon \operatorname{sen} \ell / \cos \delta
\end{aligned}
$$

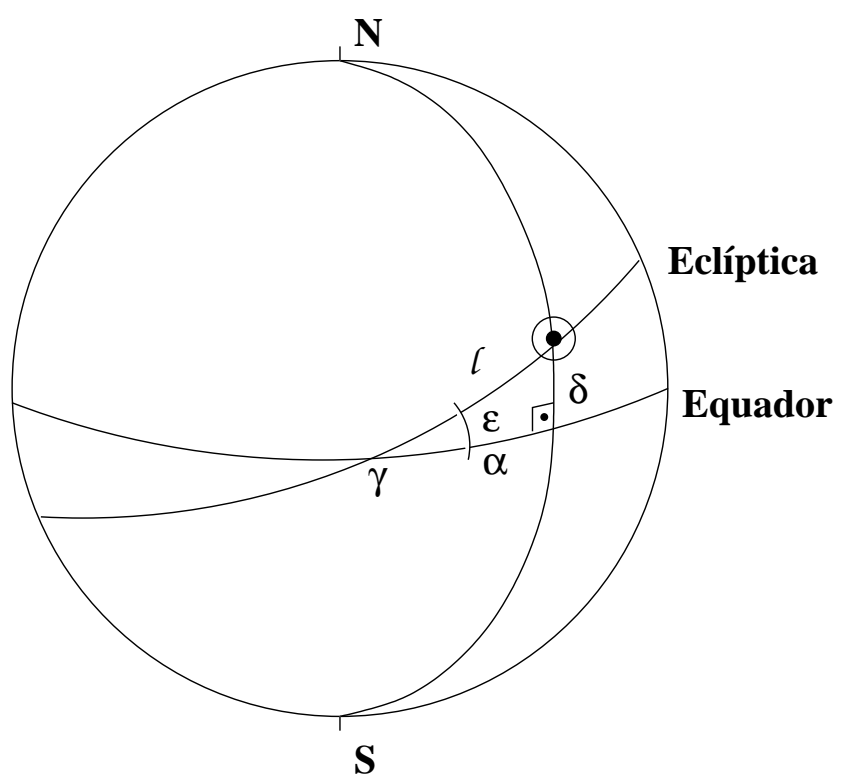

Figura 1. Representação da esfera celeste e as coordenadas do Sol $(\odot)$, com respeito à eclíptica e ao equador. A partir do equinócio vernal (ponto $\gamma$ ) mede-se a ascenção reta $(\alpha)$ no equador, e a longitude celeste $(\ell)$ na eclíptica. A distância do Sol ao equador é chamada declinação $(\delta)$ enquanto que a distância à eclíptica é conhecida como latitude celeste $(b)$. A latitude celeste do Sol não está indicada no desenho porque nesse trabalho ela é considerada nula. O ângulo entre a eclíptica e o equador é chamado obliquidade da eclíptica e é denotado como $\varepsilon$.

O ponto $\gamma$, origem da longitude celeste e da ascenção reta, também se movimenta e o componente principal desse movimento é a precessão luni-solar, de período de aproximadamente 26000 anos. Em razão dessa escala, a precessão também não será considerada em nossa análise.

Das equações (2) podemos verificar que a declinação do Sol, $\delta$, segue a evolução da longitude a menos de um fator em $\operatorname{sen} \varepsilon$. Os extremos de $\delta$ se obtêm quando sen $\ell=1 \mathrm{e}$ terão o valor de $\pm \varepsilon$, que equivalem aos dois solstícios.

De um dia para o outro, a variação máxima de $\delta$ se dá quando $\ell=\delta=0$. Considerando para nossos propósitos a

\footnotetext{
${ }^{1}$ A coordenada na direção perpendicular é chamada latitude celeste $(b)$ e, para o Sol, pode ser considerada nula, no contexto deste artigo.
} 
variação de $\ell, \Delta \ell=360 / 365.25$, em graus, deduzimos que $\Delta \delta_{\max }=\frac{360}{365.25} \operatorname{sen} \varepsilon \simeq 23^{\prime} 50^{\prime \prime}$ em um dia. Essa situação se dá próximo dos equinócios. Por sua vez, a variação diária máxima da ascenção reta $\Delta \alpha$ se dá durante os solstícios e chega a mais de $6^{\circ}$, ou $24^{m}$, em unidades de tempo. Dentro do objeto de estudo desse trabalho, ambas as variações diárias, em declinação e ascenção reta, podem ser negligenciadas. Portanto, vamos considerar que o Sol não se movimenta na eclíptica durante o período de um dia.

\section{O Movimento Diurno do Sol}

Para discutirmos o movimento aparente do Sol devido à rotação da Terra, introduzo alguns conceitos relativos às coordenadas locais. Examinemos a Figura 2. Acima do observador temos a vertical, comumente chamada zênite. Sua projeção na esfera celeste é denotada pela letra $\mathbf{Z}$. Meridiano é a linha que contém o zênite e o pólo norte (denotado por $\mathrm{N}$ ), e/ou sul. Na figura, a linha do meridiano está contida em um plano paralelo ao plano do papel. A distância entre o zênite e o pólo norte é o complemento da latitude geocêntrica do local. Esta última é definida como sendo a distância angular entre o zênite e o equador. Chamamos distância zenital $(z)$ a distância do astro ao zênite. Seu valor varia de 0 a $180^{\circ}$. O lugar geométrico dos pontos com $z=90^{\circ}$ é chamado horizonte. O complemento da distância zenital é chamado altura $(h)$. Partindo-se da direção norte, no sentido horário, define-se como azimute $(A)$ a distância angular, na linha do horizonte, até a posição onde o astro é projetado no horizonte através de uma linha perpendicular que passa pelo zênite. A distância entre o astro e o pólo norte é o complemento da declinação. Por ângulo horário $(H)$ chamamos a distância na linha do equador (omitido na Figura) entre o astro e o meridiano local. Por definição seu valor é $H=T-\alpha$, sendo $T$ o tempo sideral local e $\alpha$, a já conhecida ascenção reta. Para os fins do interesse desse artigo, será suficiente adotarmos $H$ como variável independente, representando o tempo. A origem de $H$ é o meridiano local. Antes do meio-dia seu sinal é negativo, e depois, passa a ser positivo. Embora o ângulo horário tenha relação direta com o tempo sideral, os valores deste não representam exatamente o chamado tempo legal ou universal. Isso porque este tempo, que pode ser obtido em nossos relógios de pulso, de parede etc - por mais precisos que estes sejam -, não representa a medida exata das subdivisões angulares em longitude. Pois o tempo universal, além de considerar o movimento de rotação da Terra, também leva em consideração seu movimento de translação com respeito ao Sol. Isso faz com que a diferença entre as unidades de "longitude" - que devidem a Terra em exatas 24 horas (ou 360 graus) - e as do tempo universal seja de $\sim 3^{m} 57^{s}$ ao dia. Em outras palavras, a cada vez que o Sol percorre 6 horas de tempo universal, ele percorreu, em longitude geográfica, um pouco mais de $5^{h} 59^{m}$, isto é, quase um minuto a menos. Tal diferença também será ignorada nesse trabalho.

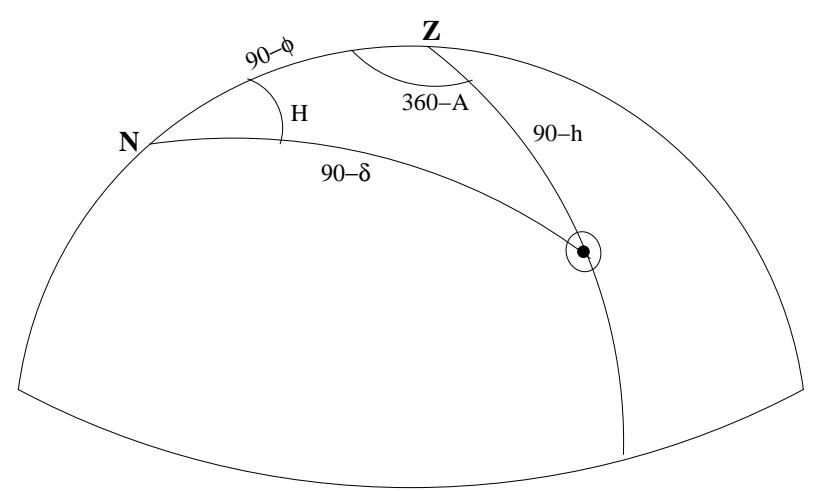

Figura 2. Transformação entre coordenadas equatoriais e locais ou horizontais. A distância do astro ao horizonte local é conhecido como altura $(h)$, enquanto que azimute é o ângulo, no plano do horizonte, entre o meridiano (no plano do papel) e o astro, a partir do norte. Por ângulo horário denotamos o ângulo entre o astro e o meridiano, no plano do equador. A latitude do local $(\phi)$ é a distância angular entre o zênite (a vertical local) e o equador.

Considerando que o Sol fique "imóvel" na eclíptica durante o período de um dia, podemos escrever facilmente as equações do movimento diurno do Sol em função das coordenadas locais referentes a uma localidade específica.

Para todos os efeitos, consideremos as coordenadas geográficas do local. Há ligeiras diferenças entre tais coordenadas e as chamadas "geocêntricas", que seriam as relevantes nesse caso. As diferenças dizem respeito a disparidades geodésicas. Entretanto na análise em questão, tais diferenças também são desprezíveis. As coordenadas do local são dadas pela longitude $\lambda$ e latitude $\phi$. As longitudes oeste são consideradas positivas. Pela convenção astronômica, as latitudes ao sul são consideradas negativas. A Figura 2 nos permite construir as equações de transformação entre coordenadas equatoriais ( $\alpha$ e $\delta$ ) para coordenadas locais: azimute $A$ e altura $h$.

Da trigonometria esférica [3], podemos escrever:

$$
\begin{aligned}
\operatorname{sen} h & =\operatorname{sen} \phi \operatorname{sen} \delta+\cos \phi \cos \delta \cos H \\
\cos h \operatorname{sen} A & =-\cos \delta \operatorname{sen} H \\
\cos h \cos A & =+\cos \phi \operatorname{sen} \delta-\operatorname{sen} \phi \cos \delta \cos H
\end{aligned}
$$

Enquanto a altura $h$ pode possuir valores que se situam entre $-90^{\circ}$ e $+90^{\circ}$ (bastando apenas uma condição trigonométrica para determiná-la completamente), o valor do azimute $A$ pode varrer os quatro quadrantes, ou seja, cresce no sentido horário a partir da direção norte, tomando o valor de $90^{\circ}$ na direção do leste, $180^{\circ} /-180^{\circ}$ ao sul e $-90^{\circ}$ a oeste. Nesse caso, são necessárias duas condições para determinálo completamente. Tendo em vista que consideramos $\alpha$ e $\delta$ constantes no período de um dia, os valores de $A$ são simétricos com relação à linha norte-sul. Assim sendo, basta considerarmos apenas a última equação em (3) para determinarmos $A$. Examinando o sinal de $H$, saberemos se $A$ encontra-se no hemisfério que contém o primeiro e segundo quadrantes, ou se está no hemisfério que contém o terceiro e quarto quadrantes. $\mathrm{O}$ sinal de $H$ elimina a indeterminação das equações trigonométricas em $A$. 
Vamos desconsiderar a refração atmosférica, pois sua importância para nossa análise também pode ser relativizada. Note-se que, nessas condições, podemos determinar o ângulo horário para o nascer e ocaso do Sol. Da primeira equação de (3), temos:

$$
\begin{aligned}
h=0 & \Rightarrow \cos H_{0}=-\tan \phi \tan \delta \Rightarrow\left|H_{0}\right| \\
& =180-\arccos (\tan \phi \tan \delta) .
\end{aligned}
$$

Como vimos, quando $H_{0}$ é negativo, será antes do meio-dia, isto é, será o nascer do Sol, e quando $H_{0}$ é positivo, será o pôr do Sol.

O domínio da função do azimute de nascer e ocaso do Sol impõe que $\tan \phi \tan \delta \leqslant 1$, ou $|\phi| \leqslant \frac{\pi}{2}-\varepsilon$. Em outras palavras, essa última condição determina a existência, na superfície da Terra, de regiões onde há períodos em que o Sol nunca nasce ou nunca se põe. Tais regiões são aquelas em que $|\phi|>\frac{\pi}{2}-\varepsilon$. São os conhecidos Círculo Polar Ártico (ao norte) e Círculo Polar Antártico (ao sul). Nessas regiões, o Sol nasce ou se põe apenas por ocasião dos equinócios. Durante seis meses o Sol permanece no céu em um movimento entre as alturas de $\phi+\delta-\frac{\pi}{2}$ e $\frac{\pi}{2}-(\phi-\delta)$.
Nos outros seis meses será noite na região. Na posição dos pólos geográficos, o Sol se mantém em altura lentamente variável, desaparecendo no horizonte quando passa para o outro hemisfério.

Além dos Círculos Polares, dois paralelos são de interesse na análise do movimento do Sol na esfera celeste. São as linhas dos trópicos ${ }^{2}$. Tais linhas são definidas pela condição $|\phi|=\varepsilon$. A zona entre as linhas dos trópicos, chamada Zona Tropical, caracteriza-se pelo fato de ser uma região onde o Sol pode chegar à altura máxima de $90^{\circ}$ (ver adiante na Seção III.2). Essa situação se dá, em geral, duas vezes ao ano, salvo quando se está sobre as linhas dos trópicos, onde o Sol chega a $90^{\circ}$ de altura apenas por ocasião de um dos solstícios. No hemisfério norte a linha do trópico chama-se Trópico de Câncer e no hemisfério sul, Trópico de Capricórnio. A razão desses nomes é a convenção da entrada do Sol nas casas dos signos do zodíaco ${ }^{3}$. Por causa da precessão, há muito tempo a entrada do Sol nos signos do zodíaco não coincide com a sua real posição com respeito às constelações.

Da primeira e terceira equações em (3), considerando $A=[0,180]$, obtemos as soluções:

$$
\begin{aligned}
h & =\operatorname{arcsen}(\operatorname{sen} \phi \operatorname{sen} \delta+\cos \phi \cos \delta \cos H) \\
A & =\arccos \left(\frac{\cos \phi \operatorname{sen} \delta-\operatorname{sen} \phi \cos \delta \cos H}{\sqrt{1-(\operatorname{sen} \phi \operatorname{sen} \delta+\cos \phi \cos \delta \cos H)^{2}}}\right)
\end{aligned}
$$

Se $H$ é positivo, isto é, se estivermos após o meio-dia, fazemos a transformação $A \rightarrow-A$.

\section{III.1 O Azimute no Nascer e no Pôr do Sol}

É interessante calcular o azimute do nascer e ocaso do Sol. Impondo o valor de $h=0$ e combinando a primeira e terceira equações de (3) obtemos:

$$
\left|A_{0}\right|=\arccos \left(\frac{\operatorname{sen} \delta}{\cos \phi}\right) .
$$

Sabendo que a declinação do Sol $(\delta)$ varia entre os limites de $\pm \varepsilon$, os valores limites do azimute ao nascer do Sol ficam entre $\arccos (\operatorname{sen} \varepsilon / \cos \phi)$ e seu suplementar $180^{\circ}-$ $\arccos (\operatorname{sen} \varepsilon / \cos \phi)$. Os limites do azimute ao pôr do sol são seus valores equivalentes no terceiro e quarto quadrantes. No equador, por exemplo, ao nascer, durante o solstício de verão, o Sol terá o azimute de $90^{\circ}-23^{\circ} 26^{\prime}=66^{\circ}, 567$, e no solstício de inverno, de $113^{\circ}, 433$. Na linha do Trópico de Câncer o azimute do nascente, no solstício de verão será de $\arccos (\tan \varepsilon)=64^{\circ}, 31$, enquanto que no inverno, será seu valor suplementar: $115^{\circ}, 69$. Ao contrário do que se pensa comumente, no solstício de verão local o nascer do sol nas linhas dos trópicos não se dá na direção do leste, apesar de, ao cruzar o meridiano, o Sol estar exatamente no zênite. A Figura 3 ilustra o movimento do sol no primeiro dia de verão de uma localidade posicionada no Trópico de Câncer, a $23^{\circ} 26^{\prime}$, no hemisfério norte. A mesma configuração se dá no hemisfério sul, em relação ao Trópico de Capricórnio. Neste último caso, inverter-se-iam as posições de alguns pontos de referência: o norte $(\mathrm{N})$ passaria a ser sul $(\mathrm{S})$, o oeste $(\mathrm{W})$ passaria a ser leste (E) e o Sol, na figura, movimentar-se-ia no sentido inverso.

Note-se que quando $\delta=0$, o azimute do nascer do Sol é $A_{0}=90^{\circ}$, independente da latitude, exceto no interior dos Círculos Polares. Isso quer dizer que o único instante em que o sol nasce (ou se põe) exatamente a leste (ou a oeste), é aquele em que o sol se encontra em um dos equinócios. E essa condição se verifica para qualquer latitude, tanto no hemisfério norte, quanto no sul. Foi usando essa propriedade que os antigos povos construiram marcos e miras que são iluminados apenas nos dias do equinócio.

\footnotetext{
2 "Trópico", palavra de origem grega, que entre outros sentidos referia-se, originalmente, a qualquer linha paralela ao equador.

${ }^{3}$ Ver p. ex. em Anuário Eletrônico do ON http://www.on.br
} 


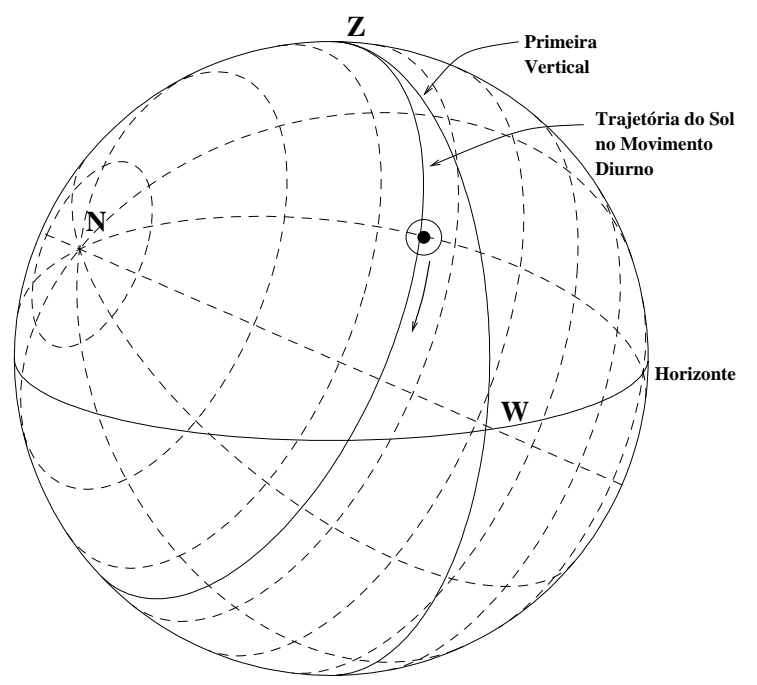

Figura 3. Esquema do movimento do Sol no primeiro dia de verão em um ponto do Trópico de Câncer. O Sol tangencia o primeiro vertical no zênite $(\mathbf{Z})$, no entanto ele nasce e se põe ao norte do observador: nasce a nordeste e se põe a noroeste. Para simular o que se passa no Trópico de Capricórnio, basta imaginar que no lugar do norte fica o sul e no lugar do oeste fica o leste.

\section{III.1.1 O nascer e pôr do sol nos limites dos Círculos Po- lares}

Quando fazemos $|\delta|=\frac{\pi}{2}-|\phi|$, teremos $A_{0}=0$ ou $A_{0}=180^{\circ}$. Isso só é possível nos limites dos Círculos Polares. A razão é simples. Como vimos na Seção anterior, a condição para o Sol nascer e se pôr é $|\phi| \leq \frac{\pi}{2}-\varepsilon$ sendo que $|\delta| \leq \varepsilon$. Assim, a latitude do local terá de obedecer, simultaneamente, as condições $|\phi| \geq \frac{\pi}{2}-\varepsilon$ e $|\phi| \leq \frac{\pi}{2}-\varepsilon$. A única solução em que essas duas condições são obedecidas é $|\phi|=\frac{\pi}{2}-\varepsilon$, isto é, o limite do Círculo Polar. Portanto, o único lugar onde $|\delta|=\frac{\pi}{2}-|\phi|$ é no Círculo Polar e tal se passa por ocasião dos solstícios. O cenário, então é o seguinte: no primeiro dia de verão, no limite do Círculo Polar Antártico, por exemplo, o sol nasce ao sul, com azimute de $180^{\circ}$, alcança a altura de $90^{\circ}-2 \varepsilon=66^{\circ}, 57$, no meridiano, e vai se pôr onde nasceu, ao sul, com azimute de $-180^{\circ}$. Por sua vez, no primeiro dia de inverno o sol nasce e se põe ao norte, instantaneamente, com $A_{0}=0^{\circ}$.

\section{III.2 A altura máxima do sol}

É dito, popularmente, que quando $h=90^{\circ}$, o sol está a pino. Tal expressão, cujo surgimento na língua portuguesa data de 1554, segundo o dicionário Houaiss [4], provavelmente vem da constatação de que quando tal ocorre, um pino não faz sombra. Nas regiões tropicais, com $|\phi|<\varepsilon$, tal condição acontece duas vezes ao ano, enquanto que nas linhas dos Trópicos, $|\phi|=\varepsilon$, ela ocorre apenas uma vez. Para sabermos quando isso acontece, usamos a primeira equação de (3), sabendo que $H=0$ e $h=90^{\circ}$. Deduzimos, facilmente, que $\delta=\phi$.

É útil saber em que época o sol fica a pino. Considerando que a longitude celeste do sol, da equação (1), pode ser aproximada para $\ell \simeq 360^{\circ} / 365,25 d$, onde $d$ é o número de dias após o equinócio vernal, podemos escrever para $d$, quando $\delta=\phi$ :

$$
d=\frac{365,25}{360} \operatorname{arcsen}\left(\frac{\operatorname{sen} \phi}{\operatorname{sen} \varepsilon}\right)
$$

usando a primeira equação de (2). Sabendo que $\operatorname{sen} \varepsilon=$ sen $23^{\circ} 26^{\prime} \sim 0,4=1 / 2,5$, obtemos, finalmente, $d \sim$ $1,015 \operatorname{arcsen}(2,5 \operatorname{sen} \phi)$. A grosso modo, nas latitudes $10^{\circ}$ e $20^{\circ}$, o sol estará a pino 26 e 60 dias após o equinócio ${ }^{4}$, respectivamente. O mesmo vai acontecer 30 e 64 dias após o solstício ${ }^{5}$.

O sol nunca atinge o zênite nas faixas de latitudes em que $\varepsilon<\phi \leq 90^{\circ}-\varepsilon$, entre o Círculo Polar Ártico e Trópico de Câncer; e $-90^{\circ}+\varepsilon \leq \phi<-\varepsilon$, entre o Trópico de Capricórnio e Círculo Polar Antártico. Isso é fácil de demonstrar examinando-se a primeira equação de (3). Para qualquer $\phi$ e $\delta$, o valor de sen $h$ atinge o máximo quando $\cos H=1$. Portanto, da trigonometria podemos obter que $h=90^{\circ}-|\phi-\delta| ; h$ será máximo quando $|\phi-\delta|$ for mínimo. Donde, toda vez que o valor máximo de $|\delta|$, para o sol, é $\varepsilon$, teremos $|\phi-\delta|=|\phi|-\varepsilon>0$, e portanto, $h$ nunca alcançará o valor de $90^{\circ}$. Regiões com essas características são chamadas Zonas Temperadas.

\section{III.3 Passagem Meridiana}

Via de regra, o Sol não cruza o meridiano local ao meio-dia. À parte o movimento do Sol na eclíptica e a correção para o tempo sideral, é preciso entender que a Terra, em seu movimento orbital, percorre uma elipse. Além disso há a perturbação da Lua e também dos grandes planetas. A diferença entre o meio-dia "legal", dado pelo relógio, e o meio-dia aparente, definido pelo instante de passagem efetiva do sol pelo meridiano, pode chegar a $17^{\mathrm{min}}$. Essa diferença é conhecida como "Equação do Tempo". A Equação do Tempo possui termos anuais e seculares. Sua dedução não é simples. É preciso obter valores para a nutação e a aberração. O melhor a fazer é evitar uma discussão nesse sentido pois nos interessa uma análise qualitativa apenas, sem que seja necessário, para fins da presente discussão, entrarmos em um debate sobre o instante em que o Sol estará em uma dada altura. O importante, para nós, é que o Sol estará a uma dada altura em uma certa época. Não sabemos o instante exato; ele estará lá em algum momento próximo do indicado.

\section{III.4 Passagem pela Primeira Vertical}

Um lugar geométrico que será de interesse na nossa análise é aquele definido pela linha, no céu, que vai de leste

\footnotetext{
${ }^{4}$ Refere-se ao equinócio de entrada da primavera no hemisfério considerado. Se no hemisfério norte, equinócio vernal, se no hemisfério sul, equinócio outonal.

${ }^{5}$ Idem: refere-se ao solstício em que ocorre o verão no hemisfério considerado.
} 
a oeste, perpendicular ao meridiano e cruzando com este no zênite. Tal linha é chamada primeira vertical.

É de interesse do nosso trabalho saber as condições em que o Sol cruza a primeira vertical. Nos dias em que tal condição é observada, o Sol cobrirá os quatro quadrantes do céu: norte-leste, leste-sul, sul-oeste e oeste-norte. Ao percorrer os quatro quadrantes, o Sol terá condições de iluminar todos os pontos de uma localidade. Se, por outro lado, o local for muito acidentado, a condição para iluminação pelo sol dependerá da análise da topografia do horizonte, o que será visto mais à frente na Seção IV.

Combinando a primeira e terceira equações de (3), obtemos, impondo $A=90^{\circ}$ :

$$
\operatorname{sen} h_{v}=\frac{\operatorname{sen} \delta}{\operatorname{sen} \phi}
$$

Para que o sol esteja acima do horizonte, a altura $h_{v}$ deve ser positiva. Impondo sen $\delta / \operatorname{sen} \phi \leq 1$, deduzimos que, para o sol cruzar a primeira vertical é preciso que $|\delta| \leq|\phi|$ com $\operatorname{Sinal}(\delta / \phi)=1$.

Verificamos, da segunda condição, que o Sol apenas cruza a primeira vertical quando está no mesmo hemisfério que a localidade estudada. Resumidamente, o Sol poderá cruzar a primeira vertical apenas na época da primavera e do verão local. Na Zona Tropical, o momento que determina essa condição é o do chamado sol a pino, visto na seção III.2. Nesta zona, no período após o equinócio (primavera para o hemisfério considerado) até o momento em que o sol fica a pino, antes do solstício, teremos que $|\delta|<|\phi|$, portanto, a condição de cruzamento pela primeira vertical é obedecida. A partir desse momento até aquele em que, após o solstício, o sol ficará novamente a pino, teremos $|\delta|>|\phi|$, e, portanto, o sol não cruzará a primeira vertical. Resumindo, na Zona Tropical o sol cruza a primeira vertical somente no período em que ele está entre o equinócio e o ponto de sol a pino. Nas Zonas Temperadas, o sol cruzará a primeira vertical em todos os dias da primavera-verão, pois sendo $\operatorname{Sinal}(\phi)=\operatorname{Sinal}(\delta)$, e o sol nunca chegando a pino, a condição $|\delta|<|\phi|$ sempre ocorrerá.

As épocas em que o sol cruza a primeira vertical são aquelas em que todos os pontos das localidades, em um momento ou outro do dia, são iluminados pelo sol. O mesmo não pode ser dito para as épocas em que o sol não cruza a primeira vertical. Nas regiões tropicais, além do período em que o sol está no outro hemisfério, existem épocas em que, curiosamente, alguns pontos da localidade nunca são iluminados pelo sol durante o período de um dia. São aquelas épocas em que sol "passou" pela latitude, seguindo em direção aos pólos. Tais pontos não iluminados são aqueles que estão "por trás" das torres com relação ao sol. Na Zona Tropical do hemisfério sul, os locais de sombra "permanente" são os que estão imediatamente ao norte das torres. Bem entendido, isso só acontece quando $|\delta|>|\phi|$, sendo o $\operatorname{Sinal}(\delta)=\operatorname{Sinal}(\phi)$. Como veremos a seguir, a sombra permanente dependerá da topografia local.

\section{Topografia do Horizonte}

A cartografia moderna se utiliza de um teodolito para a construção detalhada da topografia do local, numericamente mensurada com a precisão necessária. Na astronomia costumamos denominar essa topografia de "horizonte", em referência aos acidentes que se acrescentam à linha do horizonte impedindo a observação em dadas regiões do céu. Mais apropriadamente, chamaremos de "topografia do horizonte" à "silhueta" obtida da composição de todas as elevações entre o observador e o horizonte, que funcionam, de alguma forma, como anteparo à luz solar. As medidas com o teodolito, considerado apenas um ponto na localidade, podem ficar restritas a dimensões angulares.

Com o conhecimento prévio da latitude do lugar, podese determinar qual é a faixa do horizonte de interesse para a análise de sombras pelo sol. Uma análise qualitativa também pode ser feita com o auxílio de uma boa câmara fotográfica. Com dispositivos dessa natureza e uma boa objetiva "plana", como as câmaras de $50 \mathrm{~mm}$ de distância focal, do tipo "reflex" modernas, podemos tirar uma "panorâmica" da topografia do horizonte local. No quadro de interesse, o horizonte (plano perpendicar à vertical), o norte, o leste e o oeste devem estar bem definidos. As fotos devem ser batidas com câmara fotografica nivelada (eixo da lente deve ficar na horizontal). O uso de um nível de bolha seria recomendável. Um filme $35 \mathrm{~mm}$ com campo total de $18 \times 24 \mathrm{~mm}$ permite a cobertura de $\sim 20^{\circ} \times 27^{\circ}$ em altura e azimute totais, respectivamente. Também é possível montar uma panorâmica, com um mosaico de várias poses, em quadros contíguos, cobrindo toda a extensão do horizonte - em azimutes de leste a oeste, e em alturas de 0 a $90^{\circ}$-, desde que se tenha em mente que tal procedimento introduz uma distorção. Essa distorção decorre do fato de que, enquanto os centros de cada quadro distam uns dos outros de medidas angulares, as imagens em cada quadro são projetadas em um plano. Se o campo total por quadro é de $27^{\circ}$, a distorção em cada quadro, com respeito ao centro do campo, é de $5 \%$ para uma distância angular de $1^{\circ}$. Isso, sem levar em consideração as distorções introduzidas pelo sistema ótico da objetiva. Se a situação exigir medidas mais precisas do que essa, a análise possível é apenas qualitativa e a definitiva deverá ser perpetrada através de equipamento apropriado como, por exemplo, o próprio teodolito.

De posse dessa panorâmica, obtemos a "silhueta" do horizonte, colocada sob a relação de dimensões angulares. Para auxiliar a análise, desenhamos um diagrama, cujos componentes dependem tão somente de soluções das equações (3). Um exemplo desse diagrama pode ser visto na Figura 4. Trata-se de um gráfico no qual temos o azimute como abscissa e a altura no eixo das ordenadas. Para facilitar a análise, como já foi dito, estando no hemisfério sul, fizemos o azimute variar de $-180^{\circ}$ (sul a oeste) $\mathrm{a}+180^{\circ}$ (sul a leste). Tomamos a latitude $\phi=-22^{\circ} 54^{\prime}$ (Rio de Janeiro - RJ), como exemplo. Inicialmente traçamos as curvas do movimento diurno do sol no solstício de verão ( $\delta=+\varepsilon$, inverno no hemisfério sul) e de inverno $(\delta=-\varepsilon)$. 
Quando é verão no hemisfério sul, em regiões tropicais, o arco do movimento do sol sofre uma discontinuidade neste diagrama. Na figura, o azimute do Sol passa de $+180^{\circ}$ antes do meio-dia a $-180^{\circ}$ imediatamente após o meio-dia. Também traçamos as verticais correspondentes à primeira vertical, desenhadas, no diagrama, como linhas tracejadas longas e curtas. Em linhas pontilhadas estão desenhadas as curvas, entre os dois solstícios, ao se manter o ângulo horário constante e variando-se a declinação $\delta$. No diagrama exemplo foram escolhidos os ângulos horários variando de $-4^{h} \mathrm{a}+4^{h}$ em espaços de $2^{h}$, equivalendo, aproximadamente, aos instantes $8^{h}, 10^{h}, 12^{h}, 14^{h}$ e $16^{h}$ do tempo local. Cada linha é dividida em intervalos equivalentes a um mês. Desenhada no diagrama, a topografia do horizonte permite fazer uma análise, pelo menos qualitativa, da iluminação do sítio no período de um ano.

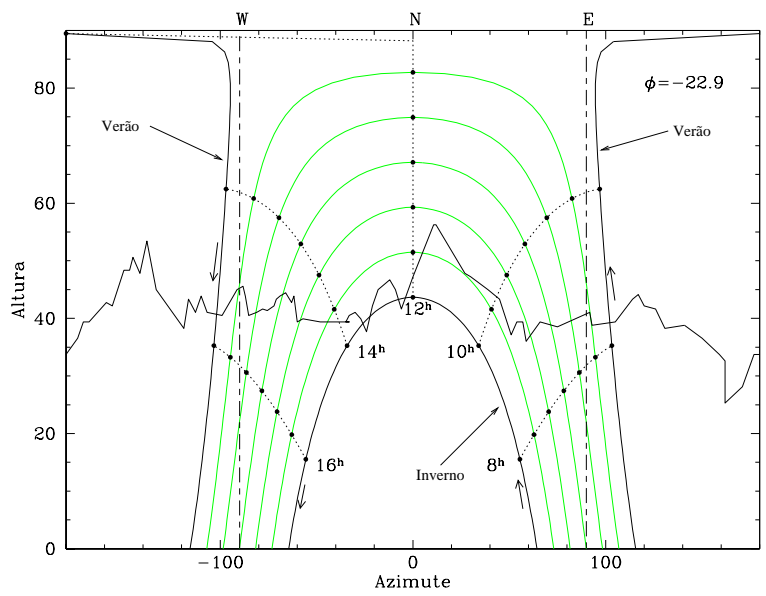

Figura 4. Diagrama de um horizonte e os arcos descritos pelo Sol entre os dois solstícios, de verão e de inverno, na latitude do Rio de Janeiro, RJ. As abscissas representam o azimute, enquanto que as ordenadas, a altura. Os arcos intermediários representam o movimento do Sol entre os dois solstícios, de mes em mes. As curvas pontilhadas representam o ângulo horário do sol de $-4^{h}$ até $4^{h}$. As retas verticais intermitentes representam a primeira vertical. A linha do "horizonte", ou a "silhueta" do horizonte está desenhada ao fundo.

Desenhamos o "horizonte" para fins de análise de insolação no local considerado. Na Figura 4, está representado um horizonte bastante acidentado. No local observamos que o sol nasce sempre após 8:00h e se põe antes das 16:00h, em qualquer época do ano. A figura mostra que perto do solstício (inverno no hemisfério sul) a insolação resume-se a alguns minutos. Esse quadro melhora nas redondezas do solstício mas é somente após (ou antes de) um mes que o local será exposto nos dois períodos do dia: de manhã e de tarde. Espera-se que tal sítio seja mais fresco que o normal na localidade do Rio de Janeiro, e é durante o inverno que ele será frio e úmido, pois não há quase incidência de luz solar sobre ele durante essa estação. Na zona rural um local com tais características favorece o plantio de fungos que seriam prejudicados com a luz do Sol.

Uma análise semelhante pode ser feita em interiores examinando-se o comportamento da iluminação do sol por uma ou mais janelas existentes no ambiente. Uma solução engenhosa para este tipo de problema foi desenvolvida pelo geofísico Ponte Neto [5]. Através de um diagrama girante sobre um diagrama fixo dependente da latitude, e com o auxílio de uma bússola, pode-se prever a iluminação do sol em uma janela, para diferentes horas do dia, em diferentes épocas do ano.

\section{Sombra Gerada por uma Torre em um Mapa}

A Figura 5 ilustra a sombra que uma torre de cota $C$ produz no plano XY, supostamente onde está desenhado o mapa de uma região. Tal sombra possui uma extensão $D$, cujo valor absoluto mantém, com a cota $C$, da torre, a relação: $D=C / \tan h$. O ponto extremo da sombra tem cooordenadas $(X, Y)$ que, em termos das coordenadas polares $(A, h)$, são:

$$
\begin{aligned}
& X=C \operatorname{sen} A \frac{\cos h}{\operatorname{sen} h}, \\
& Y=-C \cos A \frac{\cos h}{\operatorname{sen} h}
\end{aligned}
$$

Observando-se a Figura 5, e utilizando (3):

$$
\begin{aligned}
& \frac{X}{C}=\frac{\cos \delta \operatorname{sen} H}{\operatorname{sen} \phi \operatorname{sen} \delta+\cos \phi \cos \delta \cos H}, \\
& \frac{Y}{C}=-\frac{\cos \phi \operatorname{sen} \delta-\operatorname{sen} \phi \cos \delta \cos H}{\operatorname{sen} \phi \operatorname{sen} \delta+\cos \phi \cos \delta \cos H}
\end{aligned}
$$

Para uma mesma latitude e posição do Sol, é possível, portanto, construir, diagramas diferindo um do outro apenas por um fator de escala com respeito às dimensões da torre. Conhecendo-se a escala de um mapa ou planta baixa de uma localidade e a altura da torre a ser estudada, pode-se comparar as diversas posições possíveis que a sombra da torre fará no local, desprezando os efeitos de variação da latitude e longitude e a curvatura da Terra.

Como exemplo, construí um diagrama de sombra provocada pela torre do Hotel Le Meridien sobre um "croquis" de um trecho dos bairros de Copacabana e do Leme, Rio de Janeiro - RJ, que pode ser visto na Figura 6. Escolhi esta torre porque ela se destaca na paisagem de Copacabana sobrepondo-se bem acima do gabarito dos prédios vizinhos. Por cima da planta baixa do bairro, coloca-se o diagrama sob a mesma escala. Neste diagrama traçam-se as linhas equivalentes ao norte-sul e leste-oeste, as linhas que definem a sombra do ponto mais alto da torre no verão (parte de cima do gráfico), no inverno (parte inferior) e nos equinócios. Esse ponto define, aproximadamente, uma reta horizontal de ordenada igual a $\tan \phi \times$ altura da torre, esta última, no caso, de valor unitário. Além disso, linhas pontilhadas definem para dados ângulos horários, a posição da sombra em diferentes épocas do ano. Pontos cheios negros determinam os espaços relativos a um mes, nessas linhas. 


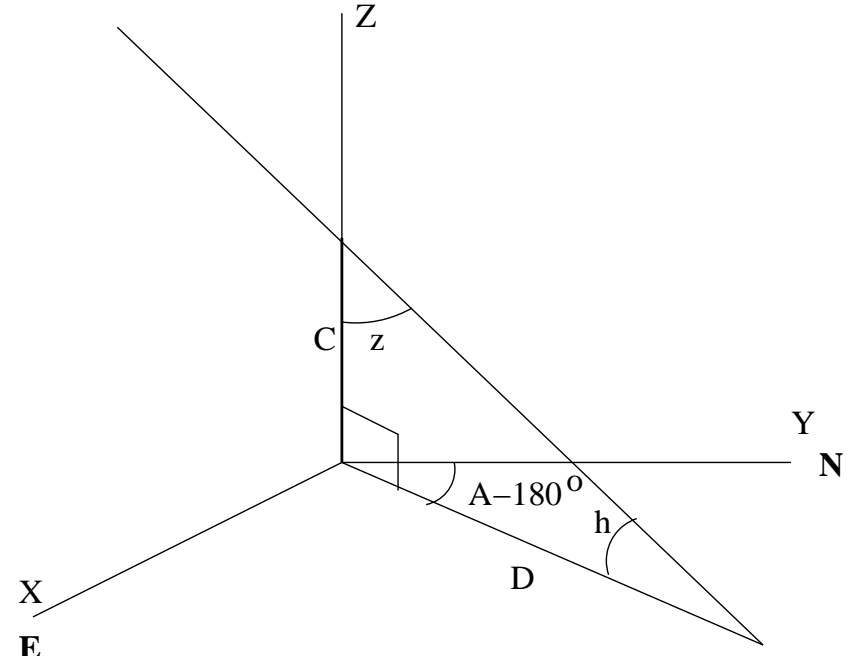

Figura 5. Uma torre de cota $C$ faz uma sombra de dimensão D em uma reta no plano XY. O eixo das abscissas aponta para o norte, enquanto que o das ordenadas aponta para o oeste. Os ângulos representados por $\mathbf{z}$ e $\mathbf{A}$, são respectivamente a distância zenital (complemento de h) e o azimute.

Da observação desse diagrama, vemos que para a praia de Copacabana, a sombra da torre não importuna de forma alguma os banhistas em qualquer época do ano, já que essa sombra incide sobre outros prédios do bairro, ou nas pistas de asfalto da Av. Atlântica. O mesmo não pode ser dito com respeito aos banhistas do Leme. Estes passam pelo transtorno de terem de mudar de lugar freqüentemente, se quiserem um "saudável banho de sol", pois a sombra se mostra maior justamente nos períodos da tarde mais propícios ao banho de sol, em uma época que vai do solstício de inverno local até um pouco depois do equinócio da primavera (ou antes do equinócio do outono). Descontada a beleza arquitetônica da torre e seu glamour como hotel de alta classe, não há dúvida que ela se impõe à paisagem. Construída em tempos de ditadura militar, é o que explica a anuência do poder público a tal agressão ao bem estar dos banhistas do bairro do Leme. Nos dias de hoje, com a existência de Sociedades de Amigos articuladas e de uma Secretaria do Meio Ambiente, dificilmente tal empreendimento teria autorização para incorporar um gabarito deste porte.

Uma análise precisa depende do conhecimento exato da altura da torre, pois o que foi apresentado aqui tem base em estimativas aproximadas. O cálculo com bases em dados exatos trará um ganho em valores numéricos, em detalhes na determinação das épocas, dias, etc. No entanto, em termos qualitativos, essa análise é plenamente satisfatória e com ela já é possível se tomar certas decisões, se este for o caso.

\section{Sombra de Volumes}

Tendo à mão a topografia detalhada da localidade é possível traçar a região de sombra de volumes que se apresentam como, por exemplo, montanhas, prédios, torres, vegetação, etc. O processo usual é a construção de maquetes e a simulação da luz solar com auxílio de spots ou refletores. De posse de um algoritmo, é possível construir códigos de programas que, examinando a topografia, são capazes de definir graficamente as regiões de sombra devido a um certo volume.

Partindo das equações (9), que determinam o ponto extremo da sombra de uma torre de altura $C$ e espessura nula, podemos escrever equações mais gerais para objetos de espessura finita. Digamos que temos, como topografia do local, uma matriz que define uma função do tipo: $z=z(x, y)$. Queremos obter, assim, um mapeamento que define sua sombra, dada a latitude do lugar, a declinação do sol e um ângulo horário. $\mathrm{O}$ conjunto de pontos sob sombra é dado pelos pontos de uma tabela $\left(X_{s}, Y_{s}\right)$. A região que determina a sombra do referido volume é um mapa de contorno que consiste na composição das curvas limítrofes definidas pelo conjunto dos pontos $\left(X_{s}, Y_{s}\right)$ :

$$
\begin{aligned}
& \frac{X_{s}}{z(x, y)-z\left(X_{s}, Y_{s}\right)}=f_{x}(\phi, \delta, H)+x, \\
& \frac{Y_{s}}{z(x, y)-z\left(X_{s}, Y_{s}\right)}=f_{y}(\phi, \delta, H)+y,
\end{aligned}
$$

onde $f_{x}$ e $f_{y}$ representam o lado direito das equações em (9), respectivamente. Como se vê, porque no denominador das duas equações aparece um termo $\left(z\left(X_{s}, Y_{s}\right)\right)$ que depende da solução, salvo casos especiais, essas equações só podem ser resolvidas numericamente. A situação é simplificada sobremaneira se considerarmos que a localidade possui apenas um volume, sendo todo o resto do local uma só planície. Desta forma podemos colocar $z\left(X_{s}, Y_{s}\right)=$ cte $=0$.

\section{VI.1 Construção das figuras de sombra em um gráfico em trểs dimensões}

De maneira geral, os softwares de visualização de figuras em 3-d não oferecem a opção de construir imagens de sombras, malgrado alguns deles permitirem escolher os ângulos de iluminação. O truque, portanto, é construir um algoritmo que permita "marcar" aqueles pontos que não podem estar iluminados, sendo dados o azimute e a altura do sol. Para tanto, vamos considerar uma matriz $N \times M$ que representa a topografia de um local a ser estudado. Dado um ponto $(i, j)$ dessa matriz, tomamos o conjunto de pontos $\left(i^{\prime}, j^{\prime}\right)$ tal que:

$$
j^{\prime}=j+\operatorname{INT}\left(\left(\mathrm{i}^{\prime}-\mathrm{i}\right) \tan \mathrm{A}\right), \mathrm{i}^{\prime}=\mathrm{i}+1 \ldots \mathrm{N} .
$$

Então, calculamos uma cota $z^{\prime}$ interpolada na reta que liga o ponto $(i, j)$ ao Sol, na esfera celeste:

$$
z^{\prime}=z_{i, j}+\tan h \sqrt{\left(i^{\prime}-i\right)^{2}+\left(j^{\prime}-j\right)^{2}} .
$$

Em seguida verificamos se $z^{\prime}>z_{i^{\prime}, j^{\prime}}$, esta última, a cota da altura do terreno no ponto $\left(i^{\prime}, j^{\prime}\right)$. Se a desigualdade for verdadeira para todos os $i^{\prime}=i+1, \ldots N$, então o ponto em $(i, j)$ estará iluminado pelo Sol. Se não for verdadeira em qualquer um dos pontos, então há um anteparo entre o ponto e o Sol, e, portanto, o ponto não estará iluminado. Em outras palavras, fazemos o traçado do raio da luz solar no caminho inverso. É como se nos colocássemos no ponto estudado $(i, j)$ e tentássemos olhar para o Sol. Se nada se interpõe no caminho, então o ponto, naquele instante, está iluminado. Do contrário, estará na sombra. 


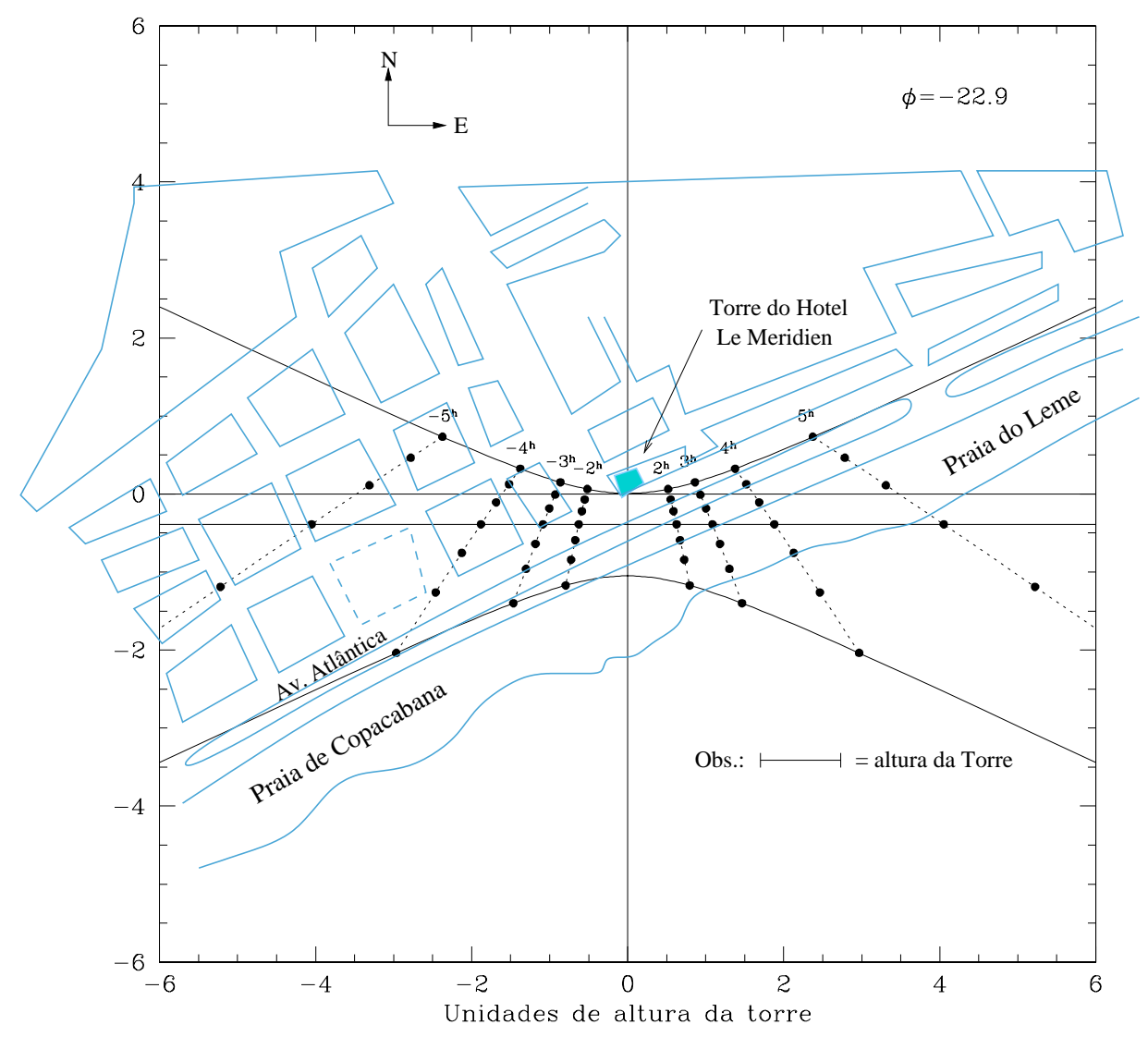

Figura 6. Diagrama de sombra da torre do Hotel Le Meridien, nos bairros de Copacabana e do Leme, Rio de Janeiro - RJ. As unidades são em altura da torre em questão. Duas curvas extremas demarcam os limites da sombra da referida torre durante o ano: o limite norte (no verão) e sul (no inverno). Tais curvas são demarcadas com pontos pretos que determinam a posição da sombra do pico da torre nos ângulos horários do sol de $-5^{h}$ até $5^{h}$. As curvas dos extremos da torre em outras épocas do ano podem ser extrapoladas pelas posições, nos mesmos ângulos horários, demarcadas pelos pontos pretos entre um extremo e outro, num espaço de 6 meses. O pico da sombra da torre nos equinócios segue uma linha reta ao sul da torre. Pode-se ver que, enquanto os banhistas da praia de Copacabana não são importunados pela sombra em época alguma do ano, aqueles que freqüentam a praia do Leme à tarde são prejudicados na maior parte do outono-inverno, como também em pequeno trecho da primavera (sem visão do pôr do Sol).

A Figura 7 mostra o conjunto de pontos com sombras de uma região modelada em curvas de nível, na latitude $-30^{\circ}$, no primeiro dia de inverno com o sol a um ângulo horário de $-2^{h}$. A sombra de uma montanha na parte norte da figura domina a região. Note-se que há uma depressão um pouco a oeste fazendo a sombra avançar naquela direção. Montanhas ao sul, fora da figura, mudam a forma geométrica da sombra.

\section{VI.2 Locais de sombra permanente}

Em função da topografia, existem locais com condições de formarem sombra permanente o ano todo. A geometria do movimento da Terra garante a iluminação solar em praticamente todos os locais, por pelo menos algum período do ano, em alguma parte do dia. Mas, é claro que até nisso há exceções. Como exemplo dessas exceções, podemos imaginar uma cratera situada dentro de uma Zona Temperada, com profundidade o suficiente para que as laterais da cratera sirvam como anteparo que se interpõe às curvas do mo- vimento do sol no céu, como num diagrama semelhante ao da Figura 4. A "silhueta" do horizonte, nesse caso, deve cobrir desde o sudeste até o sudoeste, passando pelo leste, norte e oeste.

Há casos também para os quais certos períodos, e em algumas regiões da Terra, uma torre ou elevação qualquer pode determinar que uma região contígua não receba a luz do sol no período de um dia. Essa situação pode se repetir ou não nos dias posteriores, mas o fato é que os limites dessa região de sombra são modificados no tempo.

Imaginemos, como exemplo, um muro alinhado na direção leste-oeste, com uma dada altura $D$ e uma largura $L$. Vamos construir a região sujeita à sombra permanente para um dado dia do outono ou inverno, num local em que $|\phi|>\varepsilon$, isto é, uma Zona Temperada. Ao meio-dia será o instante em que a sombra deste muro possui sua menor extensão. Ela será de $D \tan |\phi-\delta|$, como vimos na Seção III.2. 


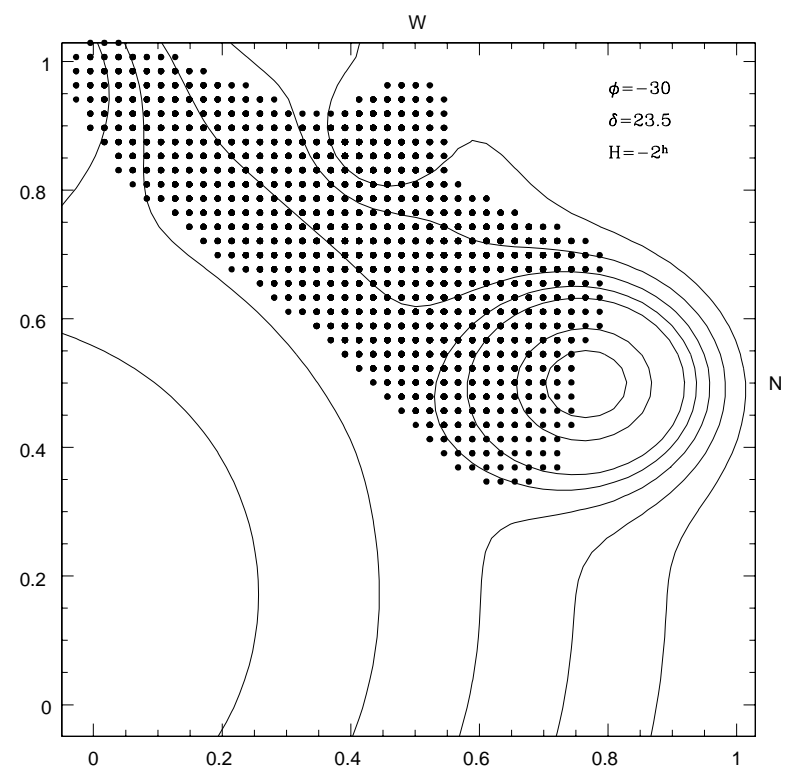

Figura 7. Figura mostrando a formação de sombra dado o diagrama de curvas de nível de uma região de latitude $\phi=-30^{\circ}$ no solstício de verão $\left(\delta=23.5^{\circ}\right)$ com o Sol no ângulo horário de $\mathrm{H}=-2^{\mathrm{h}}$. Uma depressão com centro de coordenadas perto de $(0.45,0.9)$ faz a sombra se estender para além dos limites da sombra de uma "montanha" perto de $(0.75,0.5)$.

Antes e depois do meio-dia, a sombra do muro tomará a forma de um trapézio, alongando-se ao infinito no nascer e no ocaso do sol. Nesses instantes, vão ser determinados os limites laterais da sombra permanente. Assim, se estivermos no hemisfério sul, dentro da região de sombra, o lado direito do muro projeta, ao nascer do sol, o limite direito da sombra permanente. Ao ocaso do sol, o lado esquerdo do muro determina o limite esquerdo desta sombra.

A Figura 8 mostra a região da sombra permanente de um muro retangular de altura $D$ e largura $L$. A forma desta região será triangular ou trapezoidal de acordo com a relação $D / L$ e de uma combinação entre a latitude do local e a declinação do Sol. Com efeito, vemos na figura que o limite máximo em extensão é dado por $D \tan |\phi-\delta|$. Já a altura do triângulo formado pela base $L$ e pelas projeções das laterais do muro no nascer e no ocaso do Sol é, usando a equação 6 :

$$
\frac{L}{2}\left|\tan \left(\arccos \left(\frac{\operatorname{sen} \delta}{\cos \phi}\right)\right)\right|=\frac{L}{2} \frac{\sqrt{\cos ^{2} \phi-\operatorname{sen}^{2} \delta}}{|\operatorname{sen} \delta|} .
$$

Da condição acima, é preciso que $|\phi|<90-|\delta|$ para a condição ter sentido físico. Isso significa que teremos que estar fora das regiões dos Círculos Polares para essa condição valer. Isso não é novidade tendo em conta o que já foi discutido na Seção III.2. Quando a equação (11) for superior a $D \tan |\phi-\delta|$ a figura da sombra permanente será trapezoidal, como na Figura 8, do contrário será triangular.

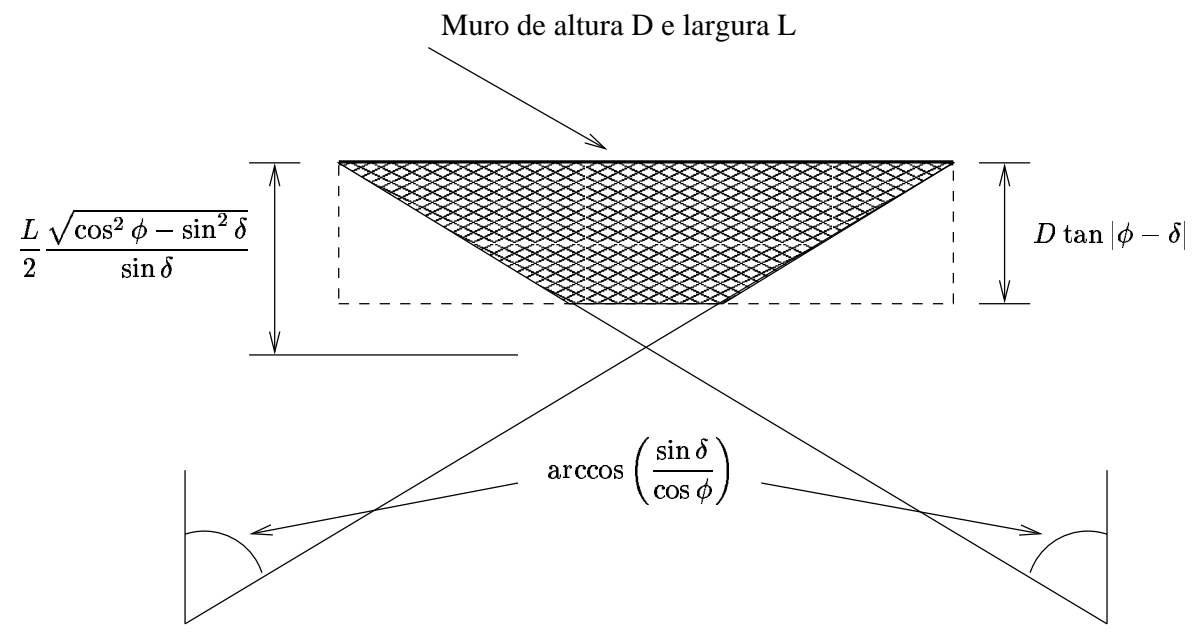

Figura 8. Limites de uma eventual sombra permanente pelo período de um dia. Tal condição acontece nas regiões temperadas no outonoinverno. Um muro de altura $D$ e largura $L$ gera uma sombra que é a composição de um retângulo de lados $L$ e $\frac{L}{2} \frac{\sqrt{\cos ^{2} \phi-s e n}{ }^{2} \delta}{\operatorname{sen} \delta} \operatorname{com} o$ triângulo de base $L$ e altura $D \tan |\phi-\delta|$, sendo $\phi$ a latitude do local e $\delta$, a declinação do Sol.

\section{Penumbra}

O Sol possui dimensões finitas. Seu diâmetro aparente é de cerca de $32^{\prime}$. Como conseqüência, as arestas das sombras de volumes no espaço não são descontínuas. A projeção da sombra não varia abruptamente nas arestas, e sim, diminui de intensidade aos poucos. À região, na área proje- tada, em que a iluminação varia gradativamente da completa iluminação à luz ambiente na sombra dá-se o nome de penumbra.

Retomemos a Figura 5. Usemos a distância zenital $z$ como variável, neste caso. Podemos escrever: $D=C$ tan $z$. O sol ocupa, por suas dimensões finitas, uma região no céu que, em termos de distância zenital, pode ser escrita como 
$\Delta z=32^{\prime}$. Como consequiência, a projeção $D$ varia de $\Delta D=C \sec ^{2} z_{0} \Delta z$. A dimensão da penumbra longitudinal de um objeto extenso no céu, depende, portanto: 1) da altura da torre, e 2) da distância zenital do objeto, no caso, o Sol. Quanto mais alta é a torre $(C)$, maior será a penumbra. Quanto mais perto do horizonte estiver o Sol, maior será, igualmente, a penumbra, tendendo a infinito no nascer e/ou ocaso. A penumbra de uma torre de $10 \mathrm{~m}$ de altura, estando o Sol a $45^{\circ}$, terá uma extensão de cerca de $19 \mathrm{~cm}$.

Analogamente, podemos deduzir que a dimensão da penumbra em azimute pode ser escrita como $\Delta x=$ $c \tan z \Delta A$, sendo $\Delta A$ a dimensão do Sol em azimute $\left(32^{\prime}\right)$. Aqui, $c$ é uma variável que assume valores de 0 a $C$, altura da torre. Comportamento semelhante ao da variação da penumbra em distância zenital, terá a penumbra em azimute ou a penumbra lateral: maior para valores crescentes de altura e de proximidade do sol com o horizonte. Em suma, a penumbra longitudinal varia $\operatorname{com} \sec ^{2} z$ e a lateral com tan $z$. Note-se que para o domínio de $z$ de 0 a $90^{\circ}, \sec ^{2} z>\tan z$, isto é, a penumbra longitudinal é sempre maior do que a lateral. Ambas são diretamente proporcionais à altura considerada.

É possível estimar a variação de intensidade da penumbra, considerando que o disco solar possui intensidade uniforme, o que é uma aproximação razoável para nossos propósitos. Sendo assim, a intensidade da penumbra depende tão somente da área exposta, isto é, aquela não obstruída pela torre. Seja $s=d z / 32^{\prime}$, com $d z=\left[0,32^{\prime}\right]$. Portanto, $s$ assumirá valores entre 0 e 1 . A área do segmento do círculo de diâmetro unitário, em termos da variável $s$ é: $R(s)=\pi-\arccos (1-2 s)$. A queda de iluminação na penumbra que segue a curva $R(s) / \pi$ é ilustrada na Figura 9. A iluminância devida ao Sol passa de um valor de $100 \%$, quando todo o seu disco está exposto, a zero, quando todo o disco é obstruído. É claro que a iluminância absoluta no local determinado não será nula. Sempre haverá iluminações secundárias advindas de outros pontos, por reflexão da própria luz solar ou de outras fontes de luz.

\section{Conclusão}

No que tange à análise qualitativa, podemos descrever, com razoável aproximação, o movimento do Sol percorrendo $360^{\circ} \mathrm{em}$ um ano. Iniciando pelo equinócio vernal, no ponto $\gamma$, o sol descreve um movimento que pode ser traduzido em equações trigonométricas simples, em termos das coordenadas equatoriais $\alpha$ e $\delta$. A declinação atinge seus extremos durante os solstícios, e cruza a linha do equador duas vezes ao ano, determinando os equinócios vernal e outonal. No limite das aproximações aqui adotadas, o movimento do Sol, com respeito ao equador, pode ser considerado uniforme e "imóvel" no período de um dia.

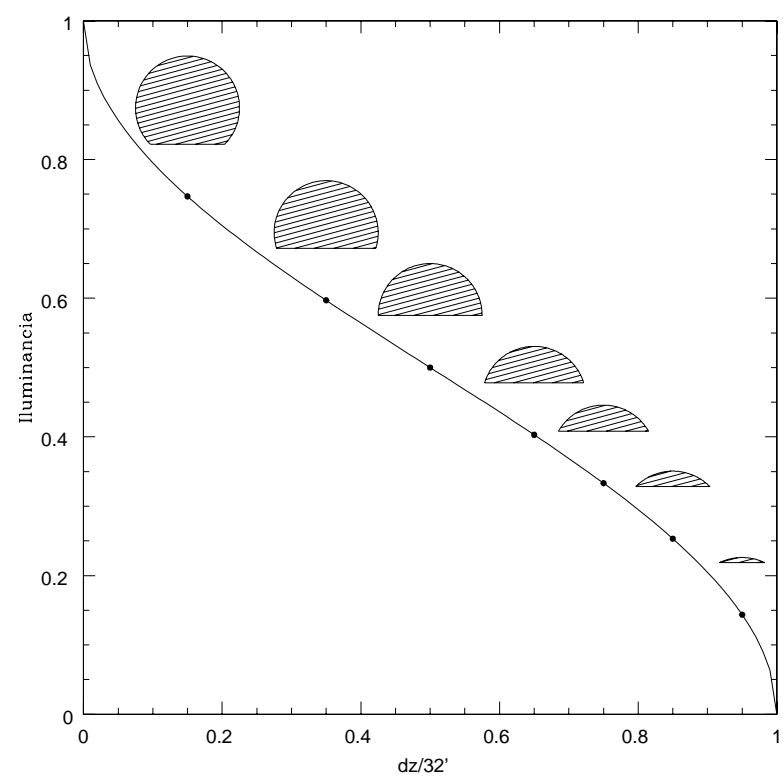

Figura 9. Gráfico mostrando a queda na iluminância devido à obstrução do Sol por uma torre de altura arbitrária, definindo a região da penumbra. A dimensão da penumbra deve ser ampliada por um fator proporcional a $\sec ^{2} z$ ou $\tan z$, dependendo se a penumbra é longitudinal ou transversal.

Determinando os ângulos horários em que o sol nasce e se põe, chega-se às regiões dos Círculos Polares, onde não há nascer e ocaso diário, apenas o equinocial. A Zona Tropical e Zonas Temperadas são delimitadas pela possibilidade do sol chegar ou não a pino em determinadas épocas do ano. Pode-se concluir que, salvo algumas exceções, todas as regiões abertas são iluminadas de uma forma ou de outra pela luz solar em algum período do ano. No entanto, sombras permanentes durante o dia podem vir a se formar e isso acontece durante o outono-inverno local. Curiosamente, na Zona Tropical, sombras permanentes também podem se formar durante a primavera-verão.

Diagramas do caminho do Sol com respeito à topografia do horizonte podem ser construídos a partir de fórmulas simples para o movimento do sol, tendo como único parâmetro a latitude geográfica local. Do mesmo modo, um diagrama dos limites de sombra durante o ano pode ser construído sobre a planta baixa, bastando para isso conhecer a latitude e, é claro, o mapa local.

Formas de sombra podem ser previstas, inclusive aquelas eventualmente permanentes. Pode-se também desenhar a forma de uma sombra de um volume determinado em um local acidentado, partindo-se da carta topográfica ou conhecendo-se a cartografia da região. Nas extremidades da sombra observa-se a penumbra, que depende tanto da altura do Sol como da dimensão do objeto que serve de anteparo.

\section{Agradecimentos}

Agradeço aos colegas Newton P. dos Santos, Cosme Ponte Neto e Fernando Dias pelos valiosos comentários e sugestões e a Sonia Alberti pelo auxílio à revisão da redação. 


\section{Referências}

[1] Jeans Meeus, Astronomical Algorithms, Willmann Bell, Inc., (2000).

[2] Walter Maciel, Astronomia e Astrofísica, IAG-USP, (1991).

[3] Roberto Boczko, Astrometria, In Maciel [2], (1991). Capítulo
I, 3-23.

[4] Antônio Houaiss, Dicionário Eletrônico Houaiss. Editora Objetiva, (2001).

[5] Cosme Ponte Neto, Estudo da Insolação nas Edificações, Comunicação Pessoal, (2002). 